\title{
ENTRE A CRUZ E A ESPADA
}

\section{BETWEEN THE CROSS AND THE SWORD}

Adriana Pinto de Mello ${ }^{1}$

Adriana Pinto de Mello. Entre a Cruz e a Espada. Rev Bras Crescimento Desenvolv Hum. 2010; 20(1): 106-111

\section{Resumo:}

Este trabalho é o relato da história e das atividades do Projeto Qorpo Santo, um projeto coletivo e interinstitucional que se propõe a construir alternativas de desinternação e de reinserção na comunidade para os pacientes longamente internados, em cumprimento de Medida de Segurança, no Instituto Psiquiátrico Forense Maurício Cardoso (IPF), em Porto Alegre/RS. Trata-se de uma experiência na qual a existência de diferentes olhares aponta possibilidades diversas de leituras e intervenções. Tendo como referencial a Lei da Reforma Psiquiátrica, o trabalho procura problematizar a atenção em saúde mental ao paciente judiciário. A direção proposta é, por um lado, a promoção da autonomia do paciente, o resgate da sua palavra, a sua responsabilização pelos seus atos e suas escolhas e, por outro, o reconhecirnento do paciente judiciário como cidadão, usuário de sistema de saúde e sujeito de direitos.

Palavras-chave: psiquiatria; política social; psiquiatria comunitária.

\section{Abstract:}

This study is the report of the history and activities of the project Qorpo Santo, a collective and institutional project which proposes alternatives for discharge and reintegration in the community for long hospitalized patients in compliance with Measure of Security in the Forensic Psychiatric Institute Maurício Cardoso (IPF), in Porto Alegre-RS. This is an experiment in which the existence of different views presents various possibilities for readings and interventions. Taking as reference the Law of the Psychiatric Reform, the study aims to question the mental health care to the judiciary patient. The management proposal is on the one hand, the promotion of patient autonomy, the redemption of his word, their accountability for their actions and their choices and, secondly, the patient's legal recognition as a citizen, user of the health system and individual with rights.

Key words: psychiatry; public policy; community psychiatry.

Recorte da monografia vencedora do eixo diretrizes para o sistema penitenciario, no concurso promovido por ocasião da CONSEG Sua publicação integral pode ser lida em: BRISSET-BARROS, F.O. Por uma política de atenção integral ao lou infrator. Belo Horizonte: Del Rey. 2009. (no prelo).

1 Psicóloga, Especialista em Psicologia Jurídica, Especialista em Psicologia Clínica, Psicóloga na Vara de Execução das Penas e Medidas Alternativas- Poder Judiciário RS, integrante do Grupo de Trabalho para Reabilitação Psicossocial dos Paeientes do IPF do Projeto Qorpo Santo. E-mail: a.mell@terra com.br 
Esta é uma história de várias histórias que tiveram o seu movimento inercial interrompido. É um relato de conquistas e dificuldades, mas, acima de tudo, é a narrativa sobre o efeito do entranhamento, da dúvida e da esperança, em roteiros que tinham um final já conhecido.

O Projeto Qorpo Santo é um projeto coletivo, que contempla uma série de ações que vêm sendo desenvolvidas a fim de promover a desinternação do paciente judiciário e a sua inclusão não só nos serviços de saúde, mas também nos demais recursos do território.

O nome escolhido é uma homenagem ao dramaturgo e poeta gaúcho José Joaquim Campos Leão (1829/1883), portador de sofrimento psíquico intenso, que produziu uma extensa obra literária. Interditado, lutou para reaver seus direitos cíveis e obteve êxito em fazer valer sua palavra. Teve sua obra reconhecida quase cem anos depois, sendo considerado um dos precursores do teatro do absurdo e da poesia moderna.

Em março de 2007, o Juiz Clademir Missaggia, titular da Vara de Execução das Penas e Medidas Alternativas (VEPMA), vara responsável pela execução das Medidas de Segurança em Porto Alegre, iniciou uma série de extinções de Medidas de Segurança de pacientes que se encontravam há muitos anos internados no Instituto Psiquiátrico Forense Doutor Maurício Cardoso (IPF).

Ao mesmo tempo em que extinguiu as medidas, determinou às equipes do IPF a eiaboração de um Plano de Desligamento para cada paciente, dando-lhes um prazo de um ano para que o paciente fosse efetivamente desinternado. Enviou, então, ofícios a diversos órgãos públicos, entidades de classe e da sociedade civil a fim de que, juntos, articulassem alternativas de acolhimento para esse paciente. Nestes dois anos de trabalho, 257 pacientes tiveram a Medida de Segurança extinta e outros 94 receberam a Desinternação Condicional.

Em 12 de Setembro de 2007, em Audiência Pública, foi determinada pela Promotora de
Justiça de Direitos Humanos, Angela Rotunno, a constituição de um Grupo de Trabalho (GT) para a construção de alternativas de desinstitucionalização e reinserção social para os pacientes do IPF. Assim, teve inicio o GT do IPF que, nestes dois anos, discutiu e vem acompanhando a situação de 150 pacientes que, juridicamente, se encontram próximos da porta de saída do manicômio judiciário mas para os quais, é necessário tecer os fios da rede de acolhimento e de atenção.

O IPF atende 700 pacientes em cumprimento de Medida de Segurança, sendo que 437 deles estão internados, 209 em Alta Progressiva, permanecendo a maior parte do tempo fora da instituição, e 54 estão cumprindo Medida de Segurança na modalidade ambulatorial. Acolhe, ainda, 28 pacientes que se encontram na Unidade de Triagem, sem situação juridíca definida. (Dados de 28 de agosto de 2009).

O movimento rotineiro, inercial, da Medida de Segurança, resultando em sucessivas renovações, que acabam levando a longas institucionalizações, cada vez mais difíceis de serem revertidas, possivelmente, não é uma exclusividade do Rio Grande do Sul, nem é uma responsabilidade de uma instituição em particular. Para ser mantido é necessária a ação, ou omissão, de juizes, promotores, defensores, advogados, psicólogos, assistentes sociais, psiquiatras. $^{1}$

O número significativo de pacientes longamente institucionalizados; o tamanho da Hospital de Custódia e Tratamento Psiquiátrico (HCTP) do Rio Grande do Sul, possivelmente o maior do país; as condições de exclusão e estigmatização próprias às instituições totais e a dificuldade para a participação do paciente do IPF na vida da cidade, foram o mote para a ação do Juiz, as iniciativas do Ministério Público e o engajamento de todas as instituições e profissionais que têm participado da Projeto Qorpo Santo.

A desconstrução do estabelecido, dc conhecido, é sempre uma tarefa ardua, mas a rea- 
lidade destes pacientes foi despertando em cada um de nós, representantes de setores diferentes e de instituições distintas, o estranhamento e a inconformidade que mantêm o grupo em movimento, grupo este que vem crescendo em componentes e em parceiros. $^{2}$

Diante deste amplo desafio, a alternativa encontrada foi, justamente, partir da situação mais particular, a história de cada paciente, suas potencialidades, suas fragilidades e o trabalho que vinha sendo feito pelo psiquiatra, o psicólogo, o assistente social, o advogado. Assim, passamos a conversar semanalmente sobre cada paciente em uma mesa composta pela equipe responsável pelo atendimento do caso, representantes do IPF, Secretaria de Estado da Saúde, Secretaria Municipal da Saúde, Fundação de Assistência Social e Cidadania (FASC), Conselho Estadual de Saúde e Vara de Execução das Penas e Medidas Alternativas. ${ }^{2,3}$

A discussão dos casos é um momento de retomada de cada história, de construção de uma versão sobre o percurso de cada paciente e a atenção dada a ele. Trata-se de uma experiência na qual diferentes olhares podem ter outras leituras e questionamentos sobre uma mesma narrativa, apontando alternativas diversas.

As reuniões do GT no IPF têm uma função norteadora para as demais ações do Projeto, dando encaminhamento a situações concretas, sendo uma matriz para ações semelhantes com outros pacientes e apontando as potencialidades e fragilidades da atenção ao paciente judiciário. Mensalmente são realizadas reuniões na Promotoria de Justiça de Direitos Humanos, retomando as ações do período e repensando metas e estratégias de trabalho.

O IPF passou a contar com Defensor Público, que se ocupa de questões cíveis, facilitando o acesso dos pacientes aos seus direitos.

Diante da realidade encontrada no atendimento ao paciente em Medida de Segurança, o Juiz da VEPMA impulsionou a formulação do Termo de Ajustamento de Conduta (TAC), proposta pela Promotoria de Justiça de
Controle e de Execução Criminal e pela Promotoria de Justiça de Defesa dos Direitos Humanos, que contempla os seguintes pontos:

- regulamenta a contenção física e isolamento dos pacientes, adequando o IPF às mesmas exigências feitas aos hospitais psiquiátricos, inclusive proibindo o uso de algemas de metal;

- prevê a construção de Residencial Terapêutico para pacientes em processo de desligamento do IPF;

- prevê a contratação de 24 médicos psiquiatras, 40 técnicos em enfermagem, 7 médicos clínicos, 7 assistentes sociais, 8 psicólogos, 7 terapeutas ocupacionais, 3 enfermeiros e 1 farmacêutico;

- prevê reformas nas instalações do IPF;

- regulamenta a rotina para compra da medicação evitando interrupção nc fornecimento de remédios e

- estipula rotina para a estimativa da gastos com material de higiene, devendo o Estado fornecer esse mate rial aos pacientes.

A direção proposta pelo Projeto Qorpo Santo é a promoção da autonomia do paciente, o resgate da sua palavra, a sua responsabiliza ção pelos seus atos e suas escolhas. Buscar dar voz ao paciente neste planejamento que vai sendo construído para ele e, preferencialmente, com ele.

Muitas vezes, a estratégia encontrada tem sido justamente a referência no trabalho feito em serviços menores, substitutivos ao Hospital Psiquiátrico. Um exemplo é a formação do Grupo de Reabilitação da Pensão Protegida Nova Vida, Serviço Residencia Terapêutico do Município de Porto Alegre Pacientes do IPF passam uma tarde por se mana com profissionais da Pensão Nova Vida, desenvolvendo atividades básicas do dia-a-dia como compras, passeios, preparo da alimentação. ${ }^{4}$ 
Atualmente, sete pacientes participam desse grupo, sendo que dois deles estão residindo, temporariamente, na Pensão Nova Vida, numa passagem para voos mais distantes e independentes. Assim, é no acolhimento próximo, no ritmo da vida comum, mas que para os pacientes tem o encanto, o cheiro e o gosto caseiro e pessoal, que alguns pacientes estão podendo vivenciar as buscas e encontros com um futuro possível. Como disse Luis Pedro, que na noite de seu aniversário pediu para dormir na Pensão, justificando: "quero ter um encontro comigo mesmo".

É emblemática a história do paciente Valdomiro, que ingressou no IPF em 1990, aos 20 anos de idade, após tentar praticar um furto. Em Dezembro de 2007, seu caso foi discutido no GT do IPF. Valdomiro não sabia ao certo seu sobrenome, não possuía Certidão de Nascimento, muito menos outros documentos, numa inexistência civil, ainda que havendo uma existência criminal.

Segundo relato da equipe, o paciente não se vinculava às atividades propostas no IPF. Poucos meses depois, o Setor de Documentos do IPF obteve a Certidão de Nascimento do paciente, podendo encaminhar o Benefício de Prestação Continuada (BPC) da Lei Orgânica da Assistência Social (LOAS), mas principalmente descobrindo seu nome de família, resgatando o acesso à sua história. Valdomiro passou a residir na Pensão Protegida Nova Vida, depois mudou-se para outro serviço destinado a pacientes com maior autonomia e hoje mora com a companheira em uma casa com uma cuidadora que acompanha um pequeno número de pacientes, sendo supervisionada pelos serviços de saúde do município. Valdomiro tem casa, companheira, nome completo, frequenta o CAPS, tem planos de vida, estando inserido em sua comunidade.

No IPF, também foi constituída uma oficina de culinária, que é coordenada pela nutricionista da casa. Para alguns, tem sido uma possibilidade de profissionalização, inclusive de acesso aos cursos do SENAI.

Para dar um panorama do trabalho que vem sendo desenvolvido, trarei alguns números sobre os 150 pacientes estudados pelo Grupo de Trabalho, sendo 138 homens e $12 \mathrm{mu}-$ lheres. Estes dados foram retirados das decisões judiciais e das informações fornecidas durante as reuniões. É um levantamento aproximado, uma vez que são informações que estão em constante mudança.

A maioria dos casos discutidos é de pacientes com Medida de Segurança extinta, 127 pacientes. Também foram trabalhados 10 casos de Desinternação Condicional; 9 pacientes foram incluídos na discussão por solicitação do TPF; 2 casos referem-se a pacientes com Medida de Segurança já extinta mas que permaneciam asilados no IPF, com autorização judicial, e 2 outras situações atípicas.

É importante salientar que mesmo antes do trabalho do GT, 82 pacientes já contavam com benefícios previdenciários: 51 deles já recebiam o Beneficio de Prestação Continuada da LOAS, 6 recebiam pensões, 25 recebiam aposentadoria ou auxilio-doença. Desde setembro de 2007, 3 pacientes passaram a receber o beneficio da LOAS e 3 outros tiveram seus benefícios encaminhados. Pelo menos, 6 pacientes não têm direito a benefícios e 5 outros trabalham.

Diante do entendimento do INSS de que os pacientes do IPF já são assistidos pelo estado, não fazendo jus ao BPC, o Projeto Qorpo Santo tem lutado para garantir a continuidade dos direitos beneficiários do paciente judiciário, fundamental para a construção de projetos de reabilitação psicossocial e de promoção da autonomia.

Também houve um incentivo para o cadastramento dos pacientes desinternados no Programa de Volta para Casa. Antes do trabalho do GT, havia 8 pacientes egressos do IPF recebendo o benefício. Desde o início do tra- 
balho do GT, foram incluídos mais 60 pacientes no programa.

Dos pacientes estudados, 22 já moravam "em casa", sozinhos, com amigos ou familiares. A partir do trabalho realizado, mais 27 pacientes passaram a morar em casa, 3 pacientes estão morando em Serviços Residenciais Terapêuticos, 2 pacientes residem em casas de cuidadores, 25 pacientes passaram a morar em instituições com características asilares e 1 paciente em Medida Ambulatorial deixou de se apresentar no IPF. Ainda hoje, 45 pacientes permanecem residindo no IPF e 5 outros, apesar de continuar morando no IPF, estão vinculados ao Grupo de Reabilitação da Pensão Protegida Nova Vida. Não dispomos da situação atualizada de outros 20 pacientes.

A alternativa encontrada para alguns pacientes está distante do que seria ideal e acaba resultando em um processo de transinstitucionalização. Trabalhamos com estas limitações, sem ignorá-las e tentando apontar, a médio e longo prazo, outras opções, como o aumento de vagas disponíveis em Serviços Residenciais Terapêuticos. $^{5}$

Há uma preocupação constante em promover a circulação dos pacientes pelos serviços de saúde e outros por outros espaços da rede social, diminuindo a dependência do manicômio judiciário e procurando construir novas referências. Quando começamos a acompanhar estes pacientes, apenas 5 deles estavam vinculados a serviços de saúde externos ao IPF. Atualmente, outros 41 pacientes estão vinculados aos serviços de saúde.

Cabe ainda apontar que 8 pacientes desse grupo de 150 faleceram neste período. Mas é significativo que a única situação de grave violência tenha como vítima um paciente, a quem chamaremos de João, que já estava desinternado, mas que, por ser paciente do IPF, encontrou dificuldade no acolhimento na rede de saúde pública de sua cidade. Desorganizouse e retornou espontaneamente ao IPF, local que tinha como referência, permanecendo em unidade fechada. João foi agredido por outro paciente, no interior da instituição, permanecendo 5 meses em coma e vindo a falecer. Talvez a sua história nos traga alguns ensinamentos sobre a relatividade da proteção oferecida pela institucionalização, do conceito de periculosidade e sobre a importância de haver uma rede que dê conta da atenção ao paciente judiciário. Uma rede que não seja interna ou externa ao manicômio, mas que pense nas alternativas de inclusão do paciente desde o início da Medida de Segurança, ou ainda antes.

Estamos, também, planejando um sistema de acompanhamento dos pacientes, por pelo menos um ano após o recebimento do Alvará de Soltura, com o objetivo de avaliar o processo de desinstitucionalização e realizar correções necessárias no projeto.

Há efetivamente uma proposta de modificar a atenção ao paciente judiciário, recebendo este paciente como um usuário do sistema de saúde, como de fato o é, colocando o acento na escuta do paciente, e na construção, com ele, de alternativas de vida. Essa proposta exige, de todos, uma modificação na sua posição e no seu fazer. Um encontro com o novo, um convívio com outras instituições, um trabalho que atravesse os muros do manicômio. ${ }^{6}$

Nesse sentido, temos avaliado como fundamental desenvolver atividades de articulação e capacitação da rede de atendimento interna e externa ao IPF. Numa parceria entre Secretaria de Segurança Pública, Secretaria de Estado da Saúde, Secretaria Municipal da Saúde e VEPMA, foi enviado ao Ministério da Justiça um amplo projeto de capacitação chamado "EDUCAÇÃO EM SAÚDE: Implantação de um Programa Permanente de Reabilitação Psicossocial no Instituto Psiquiátrico Forense".

Foram ainda realizados três seminários sobre os temas: periculosidade, redes de atenção ao paciente judiciário e alternativas de cuidado em saúde mental.Neste momento, em Porto Alegre, estamos tendo o Encontro Estadual de Saúde Mental, onde houve uma roda 
de conversa, justamente, sobre a temática da Medida de Segurança.

Colocar em pauta o tema da atenção ao paciente judiciário, das possibilidades que as propostas da reforma psiquiátrica trazem para esse atendimento, garantir que diferentes olhares se voltem para esse paciente já faz a diferença, aponta alternativas, abre portas, algemas e portões, que uma vez abertos, exigem a construção de acessos e de caminhos na comunidade.

Neste lugar híbrido, entre a cruz e a espada, entre o saber do direito e o saber médico e de outras disciplinas da área da saúde e da assistência social, o louco infrator, o manicômio judiciário e a medida de segurança permanecem como escravos de dois senhores, tendo que atender às propostas e às regras de discursos diferentes, legitimando absurdos inaceitáveis, como a permanência de um paciente institucionalizado durante 11 anos por ter quebrado uma janela e chutado o cunhado. O paciente internado no HCTP, ao menos no Rio

\section{REFERÊNCIAS}

1. Amarante, P. Saúde Mental e Atenção Psicossocial. Rio de Janeiro: Fiocruz, 2007.

2. Barros, FO. PAI-PJ - Projeto de Atenção Interdisciplinar ao Paciente Judiciário. Cadernos de Textos. III Conferência Nacional de Saúde Mental. Ministério da Saúde. Brasília, dezembro de 2001. Disponivel em: http://portal.saude.gov.br

3. Brasil. Ministério da Saúde/Ministério da Justiça. Seminário Nacional para a Reorientação dos Hospitais de Custódia e Tratamento Psiquiátrico: Relatório Final. Brasília, setembro de 2002.
Grande do Sul, por um lado, não tem os recursos de um serviço de saúde; por outro, não tem as garantias processuais dos presos comuns. Absolvidos, são condenados a um destino incerto, onde muitas vezes tem que pagar, não só pelo delito praticado, mas pelas falhas do estado na assistência à saúde mental, pelas carências do estado e da comunidade.

Com base na fragilidade da rede de atendimento, na falta de políticas públicas para o louco infrator, o manicômio judiciário e a medida de segurança podem se apresentar como alternativas de cuidado, de cuidado continuado, constante, disponível. No entanto, a manutenção da Medida de Segurança, com a finalidade de compensar as fragilidades do atendimento, implica em riscos e violações de direitos. Manter uma pessoa cumprindo uma Medida de Segurança na expectativa de prestar-lhe a assistência que não encontra nas redes de atendimento, é como mantêla sob uma espada suspensa por um fio que pode se partir a qualquer momento e resultar no encarceramento bem intencionado, na perda da liberdade, na infantilização dos sujeitos e até mesmo em sua morte.

4. Lancetti, A. Clínica Peripatética São Paulo: Hucitec, 2006.

5. Legislação em Saúde Mental: 19902004/ Ministério da Saúde. S^a edição ampliada. Brasília: Ministério da Saúde, 2004.

6. Lobosque AM. Experiências da Loucura Rio de Janeiro: Garamond,2001.

7. Rauter, C. Criminologia e Subjetividade no Brasil. Rio de Janeiro: Revan, 2003.

Recebido em 22 de agosto de 2009. Modificado em 02 de Janeiro de 2010. Aceito em 30 de Janeiro de 2010. 